\title{
Brasil: território da produção social da abundância e da escassez
}

\author{
Patrício Aureliano Silva Carneiro*
}

\section{Resumo}

O presente artigo discute alguns fatores responsáveis pela reprodução de uma nova geografia das desigualdades no Brasil. A apropriação desigual da técnica e da renda, forjada e viabilizada pela modernização da agricultura, pela concentração fundiária, pelo êxodo rural e metropolização da pobreza e pelos privilégios do Estado outorgados à agricultura de exportação, constitui a base da construção e da sustentação de uma nova escassez socialmente produzida no país.

Palavras-chave: Malthusianismo; Modernização Agrícola; Êxodo Rural; Políticas Agrícolas; Concentração de Renda.

Brazil: territory of the social production of abundance and scarcity

\begin{abstract}
This article discusses some factors responsible for the reproduction of a new geography of the inequalities in Brazil. The unequal appropriation of technique and income - forged and done by agriculture's modernization, by the agrarian concentration, by the rural exodus and metropolization of poverty and by the privileges of the State, which are aproved of exportation agriculture - constitutes the base of the construction and the sustentation of a new scarcity socially produced in this country.

Key words: Malthusianism; Agricultural Modernization; Rural Exodus; Agricultural Politics; Concentration of Income.

Mestre em Geografia pelo Instituto de Geociências da Universidade Federal de Minas Gerais (patriciocarneiro@yahoo.com.br).
\end{abstract}

Geosul, Florianópolis, v. 24, n. 48, p 27-46, jul./dez. 2009 
CARNEIRO, P.A.S. Brasil: território da produção social da abundância e ...

\section{O debate do crescimento populacional}

Os episódios de fomes foram marcas da humanidade no período pré-industrial. Havia uma grande debilidade da ocupação humana frente a natureza. Braudel (1995) destacou que os esforços para transpor um passado voraz, monótono e frágil dos homens, em quase nada modificaram as limitações da insuficiência dos mantimentos, da população demasiadamente pequena ou grande em relação aos recursos, do trabalho improdutivo e da influência direta da natureza até o século XVII.

A estrutura da vida cotidiana estava permeada pela fome, explicada, principalmente, por crises no abastecimento alimentício em função de adversidades climáticas. Os homens lutavam contra a insuficiência de alimentos e contra as suas conseqüências, entre elas, as epidemias. A revolução agrária, na Inglaterra, com uma série de avanços como melhorias no solo, rotação acelerada de culturas e introdução de novos cereais, são alguns exemplos da modernização que, se por um lado gerou prosperidade econômica para os grandes proprietários, por outro, disseminou uma miséria jamais vista por grande parte da população rural.

$\mathrm{O}$ progresso econômico, a revolução das ferrovias e a expansão dos transportes rodoviários, o avanço na idade média do matrimônio, a redução da mortalidade urbana pelo desenvolvimento da medicina e da higiene e a queda da mortalidade infantil são alguns dos fatores que, segundo Braudel (1995), levaram ao crescimento da população mundial a partir de 1750. A tensão demográfica, decorrente de profundas transformações nas estruturas sociais, nas quais os mais pobres passaram a sofrer menos com a mortalidade, produziu um afluxo populacional, principalmente para os centros urbanos que não significou melhoria na qualidade de vida.

As calamidades contrastavam com a construção de grandes teorias sobre a perfectibilidade do homem, com as inesperadas descobertas, com a difusão do conhecimento e do espírito de pesquisa e com o novo horizonte político da Revolução Francesa. $\mathrm{Na}$ Europa, a pobreza evoluiu para um quadro grave de profunda 
miséria, agravada pela expropriação camponesa, pelo acentuado êxodo rural e pelas condições climáticas desfavoráveis.

No contexto deste crescimento populacional acelerado, também em função da redução da mortalidade, Malthus apresenta seu Ensaio sobre População em 1798. O autor procurou apontar as limitações do quadro social, afirmando que a humanidade havia ultrapassado os limites de seus poderes. As conseqüências seriam a miséria e a fome, pois a terra não teria condições de produzir os meios de subsistência face o crescimento da população. Para os adeptos da corrente malthusiana, a duplicação da população dobrava a necessidade de alimentos e de muitos outros fatores essenciais para uma forma de vida decente.

Hoje, há que se colocar que a solução do problema da fome não está na ampliação sucessiva da produção de alimentos, mas na sua redistribuição. Grande parte da população, por ser pobre, não dispõe de meios econômicos para adquirir ou produzir os alimentos de que necessita. Os adeptos do malthusianismo, na atualidade, ao estudarem a relação população e alimentação, ocultam a produção contraditória e paralela da superprodução e da fome.

\section{A reprodução da Geografia das desigualdades}

No seu Discurso sobre a Origem e os Fundamentos da Desigualdade entre os Homens, Rousseau (1989, p.32) concebe duas formas de desigualdade na espécie humana: a estabelecida pela natureza, que consiste na diferença das idades, da saúde, das forças do corpo e das qualidades do espírito ou da alma; e a

que se pode chamar de desigualdade moral ou política, porque depende de uma espécie de convenção, e que é estabelecida ou, pelo menos, autorizada pelo consentimento dos homens. Consiste esta nos diferentes privilégios de que gozam alguns com prejuízo dos outros, como ser mais ricos, mais honrados, mais poderosos do que os outros, ou mesmo fazerem-se obedecer por eles.

Nas últimas décadas, a desigualdade moral ou política se aprofundou com o fenômeno ultraliberal, principalmente em países 
pobres. Conforme relatório do United Nations Development Programme (1998), em 1960, os $20 \%$ mais ricos da população mundial detinham uma renda 30 vezes superior à dos $20 \%$ mais pobres. Em 1995, esta renda passou a ser 82 vezes maior. Para Ramonet (1998), cerca de 3 bilhões de pessoas, ou metade da população mundial, vivem com menos de 2 dólares por dia. Bauman (1999) defende que a verdadeira escala da pobreza é omitida. Segundo o autor, fala-se em 800 milhões de pessoas subnutridas, mas cerca de 4 bilhões, dois terços da população mundial, vivem na pobreza.

Na Declaração Universal dos Direitos do Homem (1948), toda pessoa tem o direito a um nível de vida capaz de assegurar sua saúde, seu bem-estar e o de sua família e sua alimentação. Os estoques de alimentos nunca foram tão abundantes, permitiriam nutrir os 6 bilhões de habitantes do planeta, com pelo menos suas necessidades diárias de 2.700 calorias. Porém, a satisfação das necessidades alimentares jamais se deu, de um modo permanente, senão para uma parte restrita da sociedade, pois conforme destacou Ramonet (1998), a cada ano, 30 milhões de pessoas morrem de fome e 800 milhões sofrem de subnutrição crônica.

No Brasil, o mapa da fome abarca, aproximadamente, um terço da população (FUNDAÇÃO GETÚLIO VARGAS, 2001). Isto equivale dizer que enquanto os portos brasileiros exportam milhões de toneladas de grãos, mais de 60 milhões de pessoas carecem das condições mais elementares para sua reprodução social. Não pretendendo esgotar o assunto, alguns fatores podem ser elencados como responsáveis pela construção e sustentação de uma Geografia das Desigualdades no país, marcada pela produção social da abundância e da escassez: a modernização seletiva da agricultura; a concentração fundiária; o êxodo rural; e a política de privilégio das exportações, questões cruciais para iniciar o debate da reprodução da desigualdade socioespacial no Brasil, materializada na concentração da renda, da pobreza e da técnica. 


\section{A modernização seletiva da agricultura}

A desigualdade foi a marca principal do crescimento da agricultura, durante o seu auge, entre os anos de 1950 e 70 (HOBSBAWN, 1995), pois ao mesmo tempo em que levou a uma intensa produção de alimentos, contraditoriamente, intensificou a fome e a miséria. Inúmeros autores defendiam que as vitórias contra a pobreza e a fome se resumiam na aplicação, em larga escala, de todos os conhecimentos científicos e tecnológicos à agricultura, visando uma maior produção e produtividade agrícola.

A modernização da agricultura atingiu seletivamente o território brasileiro, a partir da década de 1950. O Sistema Nacional de Crédito Rural, o crescimento da urbanização e das exportações e a definição de um padrão de regulação das relações sociais e econômicas do setor rural pelo Estado configuraram um modelo de desenvolvimento rural, denominado por Delgado (1985) de "modernização conservadora". Este modelo foi seletivo por regiões, aquelas com possibilidades de aproveitamento em escala empresarial; por produtos, direcionado para a expansão de culturas de exportação não tradicionais; e por produtores, voltado aos poucos e grandes latifundiários.

A transformação na base técnica da agricultura possibilitou uma revolução na produtividade agrícola, mas acentuou a dependência do território brasileiro aos interesses das grandes corporações multinacionais, produtoras de sementes, insumos e máquinas. $\mathrm{O}$ território nacional foi subjugado pelo capital estrangeiro que determina o que será produzido, regula as safras, os preços e o destino da produção e, ainda, subjuga as políticas governamentais. $\mathrm{O}$ resultado foi a substituição da produção de gêneros alimentícios básicos da sociedade brasileira pelas culturas que interessam ao mercado internacional, revelando um uso alienado do território, no que tange às suas necessidades e que produz desigualdades extremas no âmbito da geração e da apropriação da renda agrícola. A Figura 1 sinaliza a distribuição espacial do valor da produção das lavouras, permanentes e 
CARNEIRO, P.A.S. Brasil: território da produção social da abundância e ...

temporárias, nas 558 microrregiões dos estados brasileiros, segundo o Censo Agropecuário de 1995/96.

Figura 1: Valor da Produção das Lavouras Temporárias e Permanentes. Microrregiões do Brasil. 1995/96

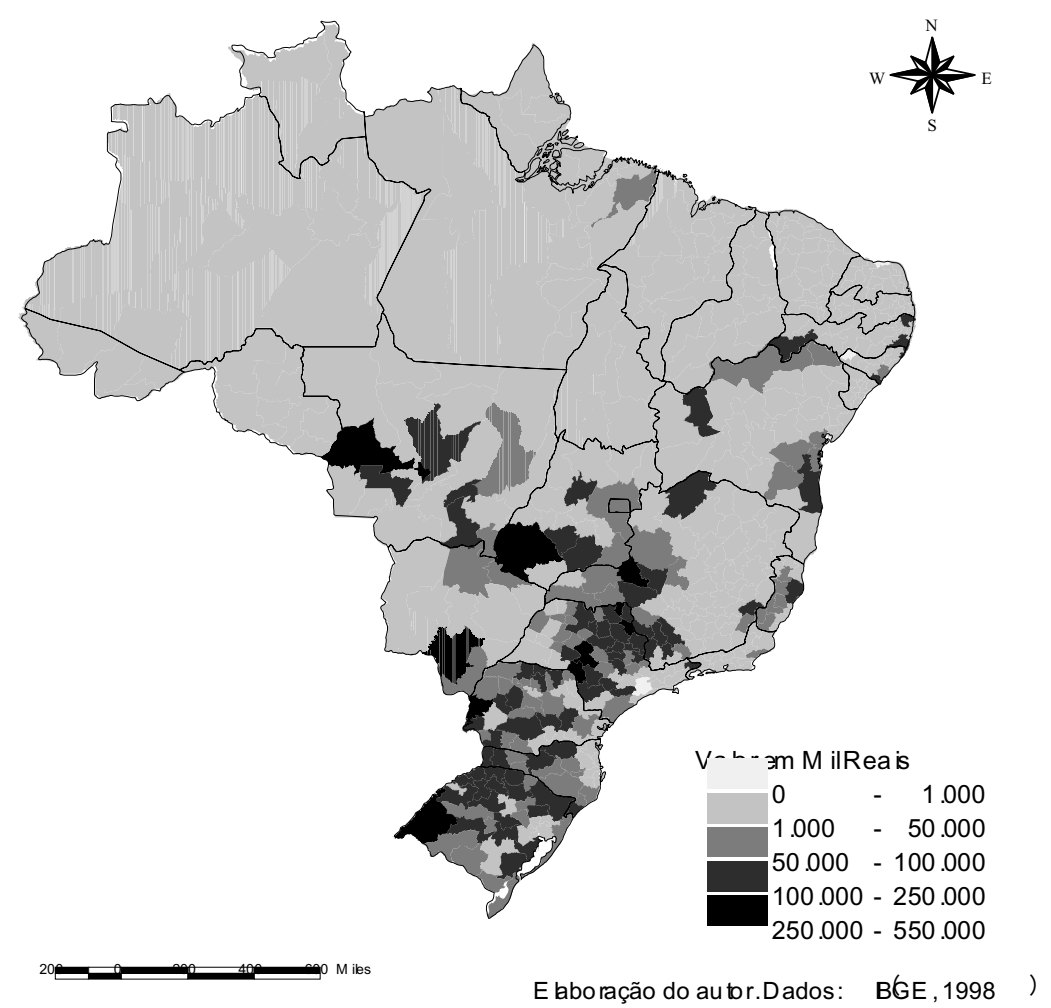

Observa-se que a maior parte da renda agrícola se concentra no Centro-sul do país, devido ao privilégio desta área no contexto da modernização das atividades agropecuárias, via amplos subsídios fiscais e financeiros concedidos pelo Estado aos produtores com culturas voltadas para exportação. Em contrapartida, grande parte das regiões Norte e Nordeste do país, e 
do Norte e Leste de Minas Gerais, a baixa expressividade e ineficiência de políticas agrícolas para os agricultores familiares, a pressão histórica das relações de dominação política e dos grandes latifúndios, o crédito agrícola e assistência técnica seletivos, o desgaste excessivo da terra devido à sua pulverização e a própria pobreza generalizada da população contribuem para a sua inserção periférica no contexto da formação da renda agrícola no país e, principalmente, no âmbito do suprimento das necessidades básicas humanas.

Ademais, destaca-se a baixa produtividade das culturas alimentares básicas do brasileiro, arroz e feijão, que entre 1970 e 1998 cresceram, respectivamente, 1,5 e 1,4 vez, ao passo que as culturas de exportação, cana-de-açúcar e soja, alvos da modernização seletiva, via incentivos fiscais e financeiros regionais, cresceram, respectivamente, 5,2 e 16,6 vezes (IBGE apud RAMALHO, 2003).

A revolução agrícola, ao produzir ilhas altamente tecnificadas no campo, beneficiou as elites comprometidas com o projeto de modernização rural. As diferentes densidades técnicas constituem agora um importante elemento de explicação da diversidade dos lugares geográficos, pois a sua distribuição desigual acarreta, simultaneamente, riqueza-abundância e pobrezaescassez no espaço (SANTOS, 1998).

\section{A rígida estrutura fundiária}

A concentração histórica da terra no Brasil é um dos maiores obstáculos à superação das diversas formas de desigualdades. A pressão territorial dos grandes latifúndios, a monocultura exclusivista, a pecuária extensiva e o modelo político que privilegia a agricultura exportadora, historicamente, obrigam os agricultores familiares, ilhados, a buscarem estratégias de sobrevivência, seja como trabalhadores arrendatários, parceiros ou assalariados nas grandes fazendas ou, ainda, a migrarem para os centros urbanos, gerando excedente de mão-de-obra pouco qualificada nas periferias. A porcentagem das terras ocupadas 
CARNEIRO, P.A.S. Brasil: território da produção social da abundância e ...

pelos estabelecimentos agrícolas, acima de 100 hectares, nas microrregiões do Brasil está representada na Figura 2.

Figura 2: Percentual das Terras Ocupadas pelos Estabelecimentos Agrícolas acima de 100 Hectares. Microrregiões do Brasil. 1995/96

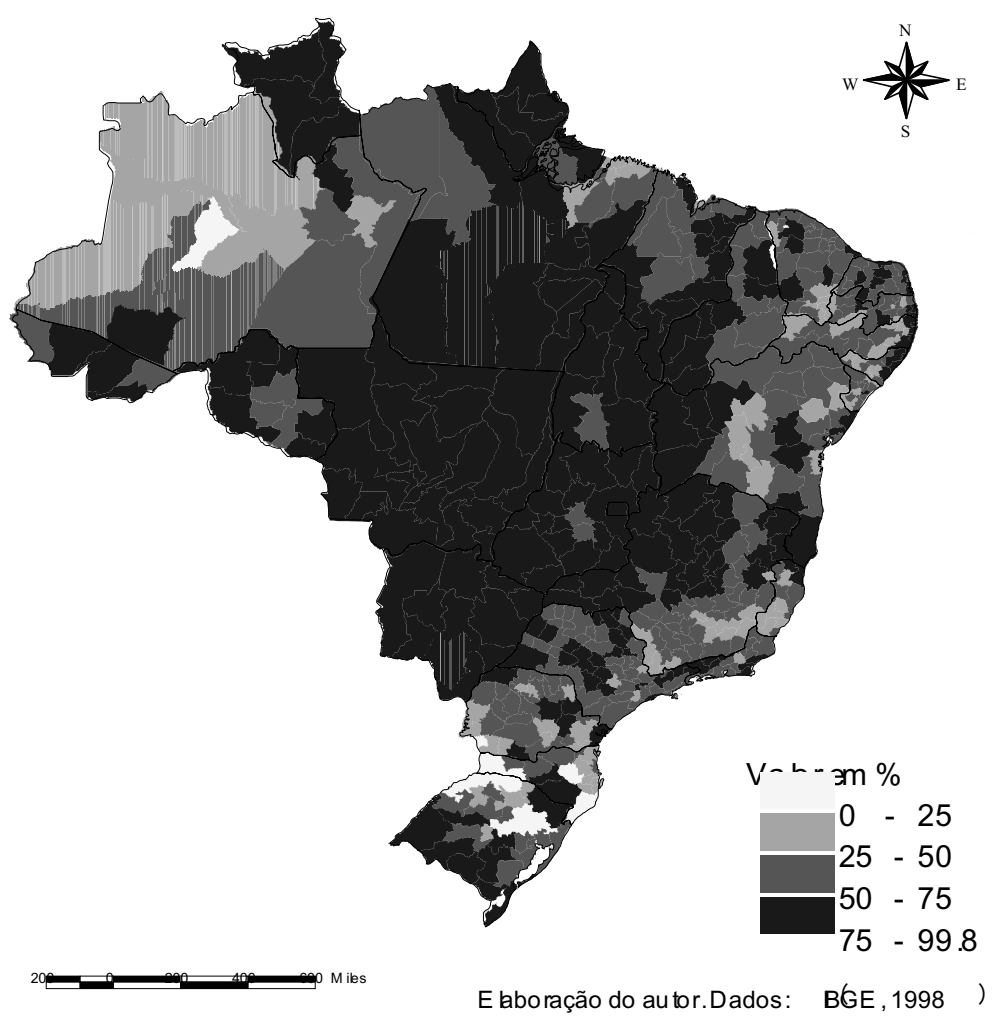

Em alguns estados, os estabelecimentos agrícolas ocupam mais de $99 \%$ da área de algumas microrregiões. A concentração excessiva da terra coincide com as áreas destinadas às monoculturas e/ou à pecuária extensiva. Genericamente, observa- 
se que o latifúndio se territorializa por quase todo o Norte, Nordeste e Centro-Sul do país.

Os agricultores familiares, vinculados à exploração extensiva da terra, são excluídos, tornando-se incapazes de competir com a exploração intensiva. Comprimem-se em ilhas no território brasileiro, geralmente com terras de pior qualidade, em virtude das de melhor fertilidade serem monopolizadas para a produção de culturas destinadas à exportação. Stedille (2000) ressaltou que dos 4,6 milhões de agricultores do país, 4,1 são familiares, com pouca terra e acessos limitados a créditos, conhecimentos e tecnologias. Os outros 500 mil detêm as maiores parcelas da terra, das tecnologias, da produção e da renda.

A efetivação de uma profunda reforma fundiária, baseada numa ampla concepção de releituras das relações políticas no campo e na concepção da terra como instrumento de trabalho daqueles que dependem, exclusivamente, dela para retirar o seu sustento, seria um importante caminho para romper com o predomínio histórico do latifúndio. Conforme estudo conjunto da FAO e do INCRA (1994), a agricultura patronal emprega poucos trabalhadores residentes e produz acentuada concentração da propriedade da terra e da renda, ao passo que a agricultura familiar possui um perfil essencialmente distributivo, supre o mercado interno com produtos alimentares de baixo custo, além de ser, incomparavelmente, melhor em termos socioculturais e ambientais.

\section{O êxodo rural e a metropolização da pobreza}

A modernização da agricultura modificou o seu papel tradicional, reduzindo, drasticamente, o acesso a terra e aumentando a instabilidade das ocupações agrícolas, impulsionando, desta forma, o êxodo rural. Martine (1990) aponta que entre 1960 e 1980, cerca de 28,5 milhões de pessoas deixaram as áreas rurais. A emigração mais intensa começou nas regiões mais desenvolvidas e não nas áreas mais pobres.

O avanço da economia industrial do Sudeste, a elevação das taxas de crescimento da população, a eliminação de barreiras 
internas das grandes regiões em função da criação de uma rede de transportes e comunicações (MATOS, 1992), os desníveis sócioeconômicos produzidos no país, a necessidade de mão-de-obra na construção civil e na indústria do Centro-Sul, as políticas migratórias de alguns estados e as secas no Nordeste (LOPES, 1976) foram outros fatores responsáveis pela grande mobilidade espacial da população brasileira para os centros urbanos. Se nas décadas passadas, a pobreza e a fome estavam concentradas, em sua maior parte, no campo e nas pequenas cidades, com os deslocamentos migratórios internos e o crescimento urbano acelerado, na década de 1970 configuraram-se grandes bolsões de pobreza nas metrópoles, potencializados pela inexistência de crédito habitacional para os pobres, pela concentração da renda e pelo fenômeno do subemprego.

Merrick e Graham (1981) sinalizaram que o desemprego tem de ser entendido no descompasso estabelecido entre o rápido aumento da população urbana em comparação ao emprego industrial. Para os autores, a tecnologia importada no modelo de substituição de importações, ao poupar mão-de-obra, gerou uma demanda maior de trabalhadores qualificados, não absorvendo grandes quantidades dos não-qualificados que também migraram na esperança de um emprego melhor nas áreas que se industrializaram.

O desenvolvimento de um setor de serviços urbanos, caracterizado pela baixa densidade de capital e rentabilidade, alto grau de ilegalidade e instabilidade ocupacional e baixos salários produziu um exército de marginalizados e empobrecidos nas grandes cidades. A falta de emprego não foi a principal explicação para a pobreza urbana nas décadas de 1960 e 70, mas o achatamento sistemático dos rendimentos auferidos pelos trabalhadores de menores qualificações. A concentração de renda contribuiu para agravar esta situação.

Atualmente, as metrópoles brasileiras apresentam graves problemas sociais como falta de emprego, miséria, marginalidade, violência, moradia, saneamento básico, fome etc. $\mathrm{O}$ 
enfraquecimento do poder do Estado, devido ao receituário neoliberal, contribui para a intensificação dos processos de marginalização e periferização da população, agravados num contexto de flexibilidade dos salários e dos empregos e da necessidade cada vez mais crescente de mão de obra especializada.

Em abril de 2004, segundo a Pesquisa Mensal de Empregos do IBGE, a taxa de desocupação foi de 13,1\% nas regiões metropolitanas brasileiras do Recife, Salvador, Belo Horizonte, Rio de Janeiro, São Paulo e Porto Alegre. Dentre estas, São Paulo representava mais da metade dos desocupados.

Rocha (2000) defende a especialização do mercado de trabalho como o indicador mais importante para explicar o aumento recente do desemprego e da pobreza. Conforme a autora, na década de 1990, as metrópoles, especialmente São Paulo, experimentaram uma deterioração dos indicadores de pobreza, como decorrente do forte impacto dos ajustamentos do sistema produtivo e do mercado de trabalho. A causa de aumento da pobreza absoluta e da desigualdade provavelmente esteve ancorada nas perdas de rendimentos que recaíram sobre os indivíduos com menor escolaridade.

A "redistribuição" espacial da população metropolitana brasileira, principalmente a partir da década de 1980, convive com a periferização do crescimento metropolitano, ou seja, em áreas cada vez mais distantes dos seus respectivos centros. A Figura 3, que exibe a distribuição espacial da porcentagem da população com rendimentos inferiores a 1 salário mínimo (R\$151,00), nos distritos do município de São Paulo em 2000, demonstra o fenômeno da periferização da pobreza metropolitana, ou seja, concentrada nos bairros mais afastados da área central.

O município de São Paulo, no ano de 2000, possuía 2.985.977 domicílios particulares, de acordo com o Censo Demográfico do IBGE. Destes, 502.802 ou $17 \%$ apresentaram rendimentos inferiores a $\mathrm{R} \$ 151,00$. Na periferia da metrópole paulista concentravam-se mais de $70 \%$ dos domicílios com tais rendimentos. 
CARNEIRO, P.A.S. Brasil: território da produção social da abundância e ...

Figura 3: Percentual dos Chefes de Domicílios com Renda Inferior a R\$ 151,00. Distritos de São Paulo. 2000

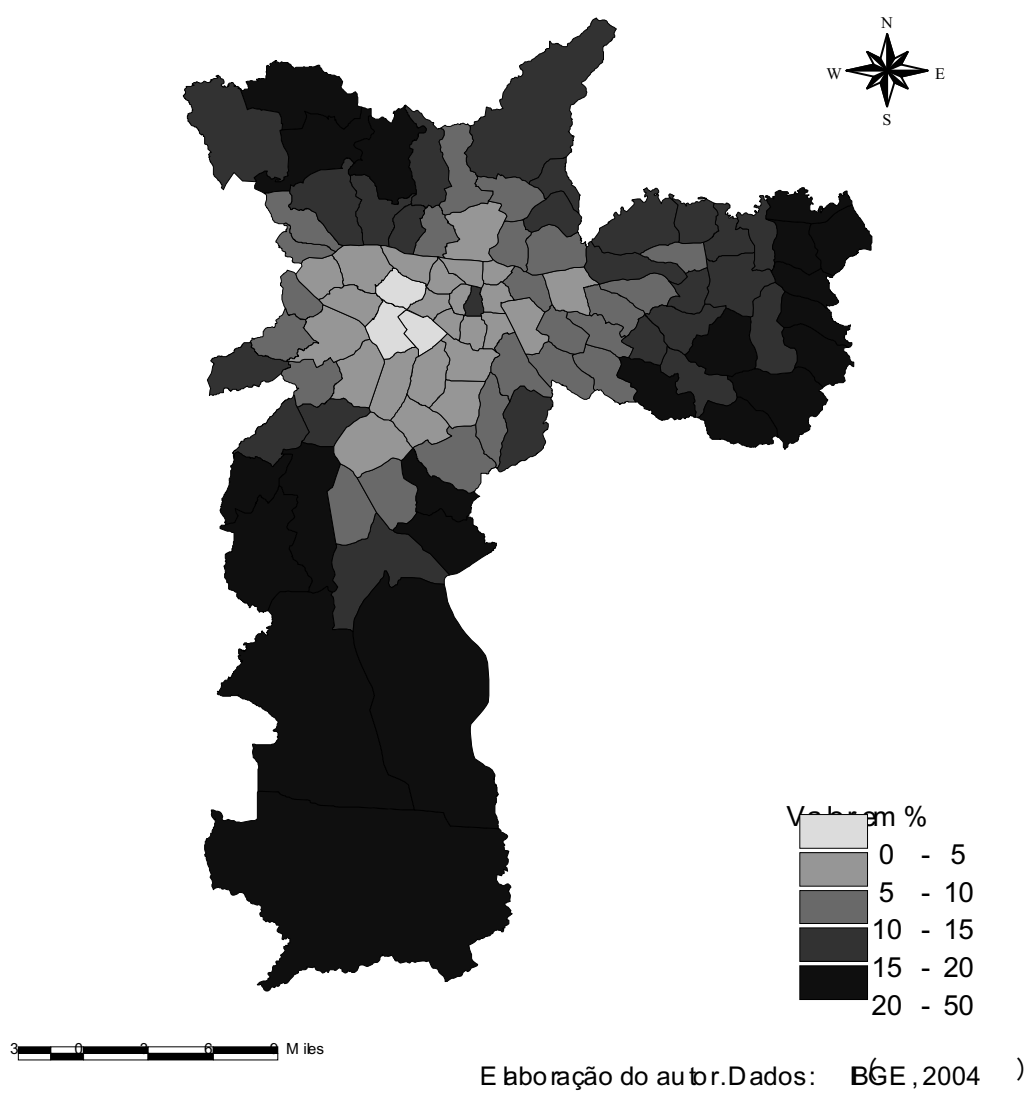

Taschner e Bogus (2001), analisando as transformações da estrutura social nas duas últimas décadas para o município de São Paulo, apontaram para uma nova geografia da centralidade e da marginalidade. Segundo as autoras, o padrão de crescimento do município tem sido de contínua expansão da mancha urbana para a periferia. As taxas geométricas anuais de crescimento populacional se apresentam maiores no chamado anel periférico. Maricato 
(1996) ressaltou que, em 1970, São Paulo tinha aproximadamente $1 \%$ de sua população morando em favelas. Em 1993, esse número alcançou 19\%, sinalizando que os anos de 1990 foram o período de explosão das favelas, principalmente nos centros metropolitanos do país. Se nas décadas anteriores o crescimento se deu pela tríade lote irregular, casa própria e autoconstrução, nos anos 90 há fortes indícios, segundo Taschner e Bogus (2001), que o crescimento se deu, sobretudo, por favelização.

A pobreza extrema, segregada e generalizada na periferia da maior metrópole produtora de riquezas do país, indica que São Paulo (cidade mundial?) tornou-se, de centro da abundância e da riqueza, a periferia da escassez e da pobreza, pois não foi capaz de gerar mínimas condições de inclusão social, principalmente em seu território periurbano, visto que seus distritos guardam realidades muito díspares.

\section{A opção política pelas exportações}

O crescimento da produção e da produtividade agrícolas no Brasil, ao mesmo tempo em que levou a uma intensa produção de alimentos, contraditoriamente, intensificou a fome e a miséria. $\mathrm{O}$ desenvolvimento da ciência e da técnica poderia acabar com a fome. Porém, os usos que se deram àquelas não foram capazes de libertar o homem de uma necessidade primordial, a de se alimentar.

Carneiro e Pereira (2005) demonstraram que desde o início da década de 1990, dados do IBGE sinalizaram um acentuado crescimento da produção de grãos no Brasil, que na última safra (2002/03) já era o dobro do princípio da década de 90, quase 120 milhões de toneladas. Em contrapartida, a produção de famintos, a partir de dados da FGV, também vem crescendo no país, correspondendo a mais de um terço da população no ano de 2000. Esse crescimento desigual, gerador de riqueza para poucos e de pobreza e fome para muitos, revela a dialética perversa entre abundância e escassez, num país que ainda é "dono" de uma das maiores áreas agricultáveis do mundo. 
A enorme contradição entre abundância e escassez indica que as políticas estatais têm incentivado mais a produção de alimentos, principalmente daqueles voltados para a nutrição animal em mercados europeus, em detrimento da produção e distribuição dos alimentos básicos para o consumo humano no mercado interno. Não basta produzir alimentos, ainda que lançando mão de todas as técnicas disponíveis, pois é preciso que o Estado e não o mercado desenvolva políticas para romper com a pobreza e crie condições para que os grupos necessitados produzam e obtenham o mínimo indispensável.

A dimensão social do problema exige provisão imediata das necessidades básicas. Porém, os programas de renda mínima, a despeito de serem importantes instrumentos de redistribuição de renda, mostram-se incapazes, por si só, de erradicarem a miséria, pois não conseguem romper o círculo vicioso de reprodução da pobreza, devendo ser implementados, conjuntamente, com outros tipos de políticas sociais redistributivas.

\section{A concentração da renda e da pobreza}

No Brasil, apesar do crescimento econômico e da modernidade terem alterado, significativamente, as paisagens, a péssima distribuição de renda contribui para que lugares tradicionalmente velhos e novos sejam atingidos pela pobreza; um fenômeno socioespacial multidimensional que se materializa na diferenciação entre famintos e alimentados, analfabetos e escolarizados, pobres e ricos, negros e brancos, entre outros; sendo diagnosticada no âmbito de dimensões como o espaço e o território, a economia e a política.

Partindo da dimensão simplificadora da pobreza, no ano de 2000, o Censo Demográfico do IBGE apontou que enquanto a parcela dos $50 \%$ mais pobres detinha $14 \%$ da renda total, esta mesma fatia era monopolizada por $1 \%$ dos mais ricos. A porcentagem da população com renda mensal per capita abaixo de $\mathrm{R} \$ 75,50,1 / 2$ do salário mínimo vigente na época, era equivalente a $47 \%$. A distribuição espacial do percentual da população com 
CARNEIRO, P.A.S. Brasil: território da produção social da abundância e ...

rendimentos inferiores a 1 salário mínimo (R\$ 151,00), nas microrregiões brasileiras em 2000, está sinalizada na Figura 4.

Figura 4: Percentual das Pessoas Chefes de Domicílio com Rendimento Mensal Inferior a R \$ 151,00.

Microrregiões do Brasil. 2000

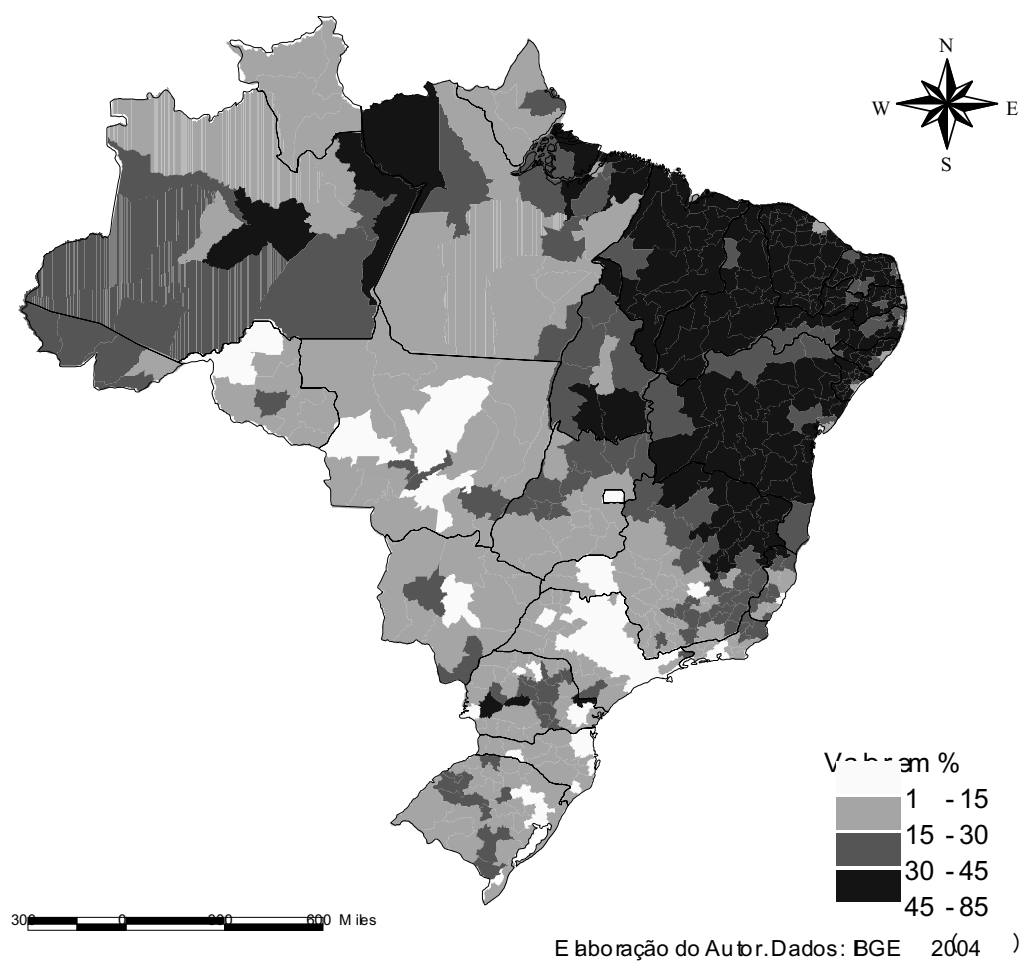

Apesar das médias mascararem a realidade do Centro-sul, em termos de porcentagem da população, as grandes regiões Norte e Nordeste, e o Norte de Minas Gerais representam os locais com maiores incidências de baixos rendimentos no país. Rocha (2003) apontou que, em 2001, a proporção de pobres no Nordeste se manteve em torno de $35 \%$ da população. Segundo a autora, esta 
região continua a representar cerca de $42 \%$ dos pobres brasileiros, um descompasso visto que participa com $29 \%$ da população do país.

Araújo (1995) assinalou que a melhoria dos níveis gerais de vida da população nordestina se deu num ritmo muito inferior ao do dinamismo da produção, e o PIB per capita esconde a forte concentração da riqueza. Segundo a autora, o principal fator responsável por esta condição social é a predominância da rigidez e das velhas estruturas econômico-sociais das oligarquias tradicionais, sempre bem situadas nas estruturas de poder.

Em termos de população total, as maiores aglomerações urbanas, das quais se destacam Porto Alegre, Curitiba, São Paulo, Rio de Janeiro, Belo Horizonte, Manaus, Belém, Fortaleza, Salvador e Recife, concentram o maior número de pessoas com rendimentos inferiores a um salário mínimo, chegando a abrigar entre 400.000 e 2.360 .000 pessoas, de acordo com o Censo Demográfico de 2000. Rocha (2000) salientou que, entre 1980 e 2000 , as regiões metropolitanas aumentaram sua participação na pobreza brasileira, chegando a abrigar, em 1997, aproximadamente $30 \%$ das pessoas com insuficiência de rendimentos no país.

Paes de Barros, Henriques e Mendonça (2001) apontaram que em 1999, cerca de 53 milhões de brasileiros eram classificados como pobres. Comparando com o observado no final da década de 1970 , os autores ressaltaram que houve melhora aparentemente estável no padrão da pobreza, mas esse valor continua moralmente inaceitável. Enfatizam que:

A desigualdade encontra-se na origem da pobreza e combatê-la torna-se um imperativo [...]. Desigualdade que surpreende tanto por sua intensidade como, sobretudo, por sua estabilidade. Desigualdade extrema que se mantém inerte, resistindo às mudanças estruturais e conjunturais das últimas décadas (PAES DE BARROS, HENRIQUES E MENDONÇA, 2001, p.23).

Simulações efetuadas pelos autores dos impactos do crescimento econômico e da redução do grau de desigualdade na 
distribuição de renda mostraram que os níveis de pobreza são mais sensíveis a alterações neste último fator do que no primeiro. Apesar de não descartarem as estratégias de crescimento econômico, chamam a atenção para o papel principal das políticas redistributivas, visto que a origem da pobreza brasileira não está na escassez, absoluta ou relativa, de recursos, mas na péssima distribuição de renda.

Apesar dessas constatações, a experiência brasileira no combate à pobreza tem reforçado a via do crescimento econômico, com poucas estratégias que dêem prioridade à redução da desigualdade. Isto permite entender porque no limiar do século XXI, conforme apontam Paes de Barros, Henriques e Mendonça (2001, p.23), o Brasil "não é um país pobre, mas um país extremamente injusto e desigual, com muitos pobres".

A acentuada disparidade econômica é a causa fundamental da geração, manutenção e ampliação de novas formas de desigualdades no Brasil. No caso específico da desigualdade alimentar, a noção de escassez, vinculada a determinismos, não tem mais sentido; o papel das adversidades naturais tornou-se marginal frente à técnica e à concentração de renda. Hoje, a escassez é socialmente produzida; é o homem que, na sua condição de pilhagem, impõe a miséria e a fome ao próprio homem.

\section{Referências bibliográficas}

ARAÚJO, T.B. de. Nordeste, nordestes: que Nordeste? In: AFFONSO, R. de B.A. (Ed.). Desigualdades regionais e desenvolvimento. São Paulo: Fundap, 1995, p. 125-56.

BAUMAN, Z. Globalização: as conseqüências humanas. Rio de Janeiro: Jorge Zahar, 1999.

BRAUDEL, F. Civilização Material, Economia e Capitalismo: séculos XV-XVIII. Tradução de Telma Costa. São Paulo: Martins Fontes, 1995. 3v.

CARNEIRO, P.A.S.; PEREIRA, M.V.F. Território da Desigualdade: Pobreza, Fome e Concentração Fundiária no Brasil 
Contemporâneo. Geografia, Rio Claro, v. 30, n. 2, p. 255-70, maio/ago. 2005.

DELGADO, G. da C. Capital financeiro e agricultura no Brasil: 1965-1985. São Paulo: Ícone/UNICAMP, 1985.

FOOD AND AGRICULTURE ORGANIZATION; INSTITUTO NACIONAL DE COLONIZAÇÃO E REFORMA AGRÁRIA. Diretrizes de Política Agrária e Desenvolvimento Sustentável. Brasília: FAO; INCRA, 1994.

FUNDAÇÃo GETÚlio VARGAS. Mapa do Fim da Fome. Rio de Janeiro: FGV, 2001.

HOBSBAWN, E. A Era dos Extremos: o breve século XX (19141991). São Paulo: Companhia das Letras, 1995.

INSTITUTO BRASILEIRO DE GEOGRAFIA E ESTATÍSTICA. Censo Agropecuário de 1995/96. Rio de Janeiro: IBGE, 1998.

2004.

Censo Demográfico de 2000. Rio de Janeiro: IBGE,

. Pesquisa Mensal de Empregos. Comunicação Social, Rio de Janeiro, IBGE, p.1-3, 25 maio 2005.

LOPES, J.R.R. Desenvolvimento e Mudança Social: formação da sociedade urbano-industrial no Brasil. $3^{\text {a }}$ ed. São Paulo: Companhia Editora Nacional; Brasília: INL, 1976.

MALTHUS, T.R. Ensaio sobre População. São Paulo: Abril Cultural, 1983.

MARICATO, E. Metrópole na Periferia do Capitalismo. São Paulo: HUCITEC, 1996.

MARTINE, G. As Migrações de Origem Rural no Brasil: uma perspectiva histórica. In: NADALIN, S. O.; MARCÍLIO, M. L.; BALHANA, A. P (Orgs.). História e População; estudos sobre a América Latina. São Paulo: Fundação SEADE, 1990, p.16-26. 
MATOS, R. A Importância das Migrações Internas no Sudeste: uma questão teórica não resolvida. In: ENCONTRO NACIONAL DE ESTUDOS POPULACIONAIS, 8., 1992, Belo Horizonte. Anais...Campinas: ABEP, 1992. 1 CD-ROM.

MERRICK, T.W.; GRAHAM, D. População e Desenvolvimento Econômico no Brasil de $\mathbf{1 8 0 0}$ até a atualidade. São Paulo: Jorge Zahar, 1981.

ORGANIZAÇÃO DAS NAÇÕES UNIDAS. Declaração Universal dos Direitos do Homem. Proclamada no dia 10 de dezembro de 1948. Rio de Janeiro: Centro de Informações das Nações Unidas no Brasil, 2005.

PAES DE BARROS, R.; HENRIQUES, R.; MENDONÇA, R. A Estabilidade Inaceitável: Desigualdade e Pobreza no Brasil. Texto para Discussão, Rio de Janeiro, IPEA, n.800, jun. 2001.

RAMALHO, M.L. Uso do Território: Técnica e Fome. In: SOUZA, M.A.A. (Org.) Território Brasileiro: Usos e Abusos. Campinas: Territorial, 2003, p.548-60.

RAMONET, I. Estratégias da Fome. Traduzido por Argemiro Pertence. Le Monde Diplomatique, Paris, p. 3-5, nov. 1998.

ROCHA, S. Pobreza e Desigualdade no Brasil: o esgotamento dos efeitos distributivos do Plano Real. Texto para discussão, Rio de Janeiro, IPEA, n. 721, abr. 2000.

Pobreza no Nordeste: a década de 1990 vista de perto. Revista Econômica do Nordeste, Fortaleza, v.34, n. 1, jan/mar. 2003.

ROUSSEAU, J.J. Discurso sobre a origem e os fundamentos da desigualdade entre os homens. São Paulo: Ática, 1989.

SANTOS, M. Técnica, espaço e tempo: globalização e meio técnico-científico informacional. São Paulo: HUCITEC, 1998. 
CARNEIRO, P.A.S. Brasil: território da produção social da abundância e ...

STEDILLE, J.P. A fome e a reforma agrária. In: FERNANDES, B. M.; GONÇALVES, C.W. P. (Orgs.). Josué de Castro: vida e obra. São Paulo: Expressão Popular, 2000, p.40-65.

TASCHNER, S.P.; BOGUS, L.M.M. São Paulo, uma metrópole desigual. EURE, Santiago, v. 27, n. 80, p. 87-120, maio 2001.

UNITED NATIONS DEVELOPMENT PROGRAMME. World Report about the Human Development. New York: UNDP, 1998.

Recebido em abril de 2008 Aceito em março de 2009 